\title{
Sensitivity and Resistant Pattern of Commonly Used Drugs in UTI in Younger Children: A Study in a Tertiary Care Level Hospital, Dhaka, Bangladesh
}

\author{
Farhana Noman ${ }^{1, ~ *, ~ G u l s a n ~ A r a ~ Z a h a n ~}{ }^{1}$, Ferdousi Hasnat ${ }^{1}$, Md. Kariul Islam ${ }^{2}$ \\ ${ }^{1}$ Department of Pediatrics, Kurmitola General Hospital, Cantonment, Dhaka, Bangladesh \\ ${ }^{2}$ International Online Journal Hub, Dhaka, Bangladesh
}

Email address:

drfarhananoman@gmail.com(F. Noman)

${ }^{*}$ Corresponding author

To cite this article:

Farhana Noman, Gulsan Ara Zahan, Ferdousi Hasnat, Md. Kariul Islam. Sensitivity and Resistant Pattern of Commonly Used Drugs in UTI in Younger Children: A Study in a Tertiary Care Level Hospital, Dhaka, Bangladesh. American Journal of Pediatrics.

Vol. 6, No. 2, 2020, pp. 146-151. doi: 10.11648/j.ajp.20200602.25

Received: February 5, 2020; Accepted: February 24, 2020; Published: March 24, 2020

\begin{abstract}
Urinary tract infections (UTIs) are one of the most common types of infections in children. Resistance to drug used in UTI is universal crisis in the present world. UTIs are usually caused by bacteria living on or in our bodies, and require treatment with antibiotics. A prospectively observational study was conducted in Kurmitola General Hospital (KGH) from January 2018 to December 2018. A total of 519 culture positive UTI children were considered for analysis. Colony counts for these samples were identified, and the profile of antibiotic resistance was identified. Here, samples with a colony count of $\geq 105 \mathrm{CFU} / \mathrm{mL}$ bacteria were considered positive. Among the children 416 children took antibiotics without prescription and among them 205 (49.2\%) was culture positive. The most common pathogen was E-coli (74.31\%) which prevailed that taking antibiotics without prescription is highly associated with the drug resistant UTI recurrent abdominal pain. Researcher took 19 antibiotics for susceptibility testing to identify the most resistant and safe drug for the UTI patients. According to the present study sensitive antibiotics were Cephradine $0 \%$, Cefotaxim $0 \%$, Imepenam $100 \%$, Cotrimoxale $46 \%$, amoxicillin and clavulanic acid $0 \%$, Cefixime $36 \%$, Cefuroxime $19 \%$, Ceftriaxone $22 \%$, Azithromycin $25 \%$, Nitrofurantoin $66 \%$, Ceftazidime $19 \%$, Ciprofloxacin 47\%, Nalidixic acid 36\%, Levofloxacin 71\% Colistin 79\%, Gentamycin 80\%, Netilmycin 80\%, Amikacin $80 \%$ and Meropenam $40 \%$. On the other hand, resistance was Cephradine $100 \%$, Cefotaxim $100 \%$, Imepenam $0 \%$, Cotrimoxale 54\%, Amoxicillin and clavulanic acid 100\%, Cefixime 64\%, Cefuroxime $81 \%$, Ceftriaxone 78\%, Azithromycin $75 \%$, Nitrofurantoin $34 \%$, Ceftazidime $81 \%$, Ciprofloxacin $53 \%$, Nalidixic acid $64 \%$, Levofloxacin $29 \%$, Colistin $21 \%$, Gentamycin 20\%, Netilmycin 20\%, Amikacin 20\% and Meropenam 60\%. So, the most sensitive drug was Imepenam $100 \%$ and the most resistant drugs were Cephradine and Cefotaxim 100\% resistance against urinary pathogens. Association between antibiotic use, drug resistance and use of with and without prescription in UTI patients was highly significant. We suggest that empirical antibiotic selection should be based on knowledge of the local prevalence of bacterial organism and their antibiotic resistance in a specific area rather than on universal or even national guidelines.
\end{abstract}

Keywords: UTI, Antibiotic Resistance, Urinary Pathogens, Resistance

\section{Introduction}

The prevalence of UTI varies with the ages of the children. It occurs in children of all ages. UTI are the most common in children under one year at age. The prevalence of a febrile symptomatic UTI in children over one year is $8 \%$ and in febrile infant is $7 \%$. Male female ratio in $1^{\text {st }}$ year of life is
2.8:5.9 and beyond 1-2 year male female ratio is 1:10 that is female more predominant. UTI in male is more common in $1^{\text {st }}$ year of life and in uncircumcised male. UTI causes end stage renal failure in $2 \%$ cases. [25-26] Furthermore many children receive antibiotics for fever, or abdominal pain or otitis media etc. without specific prescription resulting in a partially treated UTI. UTI (urinary tract infections) causes scaring the dysplasia 
reflux nephropathy. Antibiotic resistance is a global crisis in the present world and urinary tract infections (UTIs) are one of the most common types of infections. Like many human infections, UTIs are usually caused by bacteria E-Coli (80$90 \%$ ) living on or in our bodies [27-29]. and require treatment with antibiotics. But there is a proper procedure of taking antibiotics in the field of medical science and technology. However, the parents of Bangladeshi children are not yet conscious to take antibiotics for their children. Consequently, it distresses the child, concerns the parents, and may cause permanent kidney damage. Occurrences of a first-time symptomatic UTI are highest in boys and girls during the first year of life and markedly decrease after that. Febrile infants younger than 2 months constitute an important subset of children who may present with fever without a localizing source. The workup of fever in these infants should always include evaluation for UTI. UTI (Urinary tract infections) is the most common serious bacterial infection in infants and children both in community and hospital setting. UTI is an important cause of morbidly and mortality in children. [1-3] UTI is an infection of the lower urinary tract, the upper urinary tract, or both. [4] Boys are more susceptible during the first year of life; thereafter the incidence is substantially higher in girls. [5-6] Rapid diagnosis and prompt antimicrobial treatment are required to minimize the related complications, such as urosepsis, urolithiasis and renal abscess as well as the prevention of renal scarring and permanent renal-parenchymal damage. To achieve these aims an empirical antibiotic prescription is often endorsed even before the culture results are available. On the other hand antibiotic resistance of urinary track pathogens has been known to increase worldwide, specially to commonly used antimicrobials [7-9]. The increase antibiotic resistance trends are likely to have important clinical implication for the empirical used of antibiotics. For this resistance knowledge of etiology pathogens of UTIs and there antimicrobial resistance patterns in specific geographical location may help clinicians in choosing the appropriate antimicrobial [10-11]. Reporting of antimicrobial susceptibility testing of the urinary tract is usually achieved $48 \mathrm{hrs}$ following sampling, and therefore, in the majority of UTI cases, the treatment decision is empirical, being influenced by available data reflecting antibiotic resistance. For the initiation of antimicrobial therapy in UTI knowledge of the antimicrobial resistance patterns of common uropathogens in each region is essential to provide appropriate therapy. Hence, there exists a great need for antimicrobial resistance surveillance at the local, national, and international levels. The effect of resistant microorganism is obvious in hospitals and other healthcare facilities, when infections caused by drag resistant microorganism. This result in a prolonged infectivity with the related mortality and mortality especially among immune compromised patients [12]. Anyway, it is an alarming message to the medical community now is that UTIs are becoming ever harder to treat with common antibiotics. Therefore, the aim of the present study was to assess the association of drug resistance with frequent use of antibiotics without prescription in case of UTI and to identify the most resistant and safe drug.
The researcher also wants to determine the organisms responsible for UTI in school \& preschool going children and to assess the common presentation of UTI.

\section{Objectives}

\section{General Objective:}

To determine the organisms responsible for UTI in school $\&$ preschool going children.

\section{Specific Objective:}

To assess the association between antibiotic use, drug resistance and use of with and without prescription in UTI patients.

To identify sensitivity and resistant pattern of commonly used drugs in UTI in children.

\section{Materials \& Methods}

This was a prospective observational study carried out in Kurmitola General Hospital at Inpatient and Outpatient Department, Dhaka. The Ethical Committee approved this study as non-harmful and noninvasive. A total of 519 patients in inpatient and outpatients department who were presented with or without fever and high frequency of Micturition Park were enrolled in this study during January 2018 to December 2018. The unit patients were mainly from northern area of Dhaka city around Kurmitola General Hospital (Matihata, Mirpur, Bonani, DOHS, Badda, Natun Bazar and Mahakhali) Our study participants were pre-school and school going children. The parents of the patients were interviewed through questionnaire on regarding taking antibiotics. The study participants were divided into two groups on the basis of taking antibiotics with the prescription provided by the registered physicians and without prescriptions by self and other means. Then the culture test of the urine of the patients of both the groups were done through the following culture media: Urine specimen were cultured for isolation of microbial agent of UTI or blood and MacConkey and blood agar media and incubated over night at $37^{\circ} \mathrm{C}$. Then the samples were plodded out on nutrient agar and Muller Hinton agar media for colony count. Samples that showed pure growth of isolate in a count of $\geq 105$ colony forming units per $\mathrm{ml}$ of urine after overnight incubation were considered to indicator significant bacteriuria. Then Antibiotic susceptibility was done on Muller Hinton agar using disk diffusion method [30]. The results were analyzed by computer software SPSS (Statistical Package for Social Science) version 20. Unpaired t test was used to analyze the data between the groups. For analytical tests $95 \%$ confidence limit $(\mathrm{p}<0.05)$ was taken as level of significance.

\section{Result}

Total of 519 confirmed UTIs patients were enrolled to this study from in-out patient department of Kurmitola General Hospital: A Tertiary Care Hospital in Dhaka, Bangladesh. The researcher collected varieties of UTI patients' 
complaints. Among them $416(80.15 \%)$ took antibiotics without prescription and 103 (19.84) patients took antibiotics with prescription. All the patients urine 'was investigated in the lab and RE was found $325(62.6 \%)$ which was $<5$ and $194(37.4 \%)$ was $>5$. Among 416 patients who were taken antibiotics without prescription, culture positive was 205 (59.5\%) and culture negative was 211 (50.8\%). Out of 103 patients who were taken antibiotics with prescription, culture positive $(+)$ was $13(12.6 \%)$ and culture negative (-) was 90 (87.4\%). According to the present study the most sensitive antibiotics were Cephradine $0 \%$, Cefotaxim $0 \%$, Imepenam $100 \%$, Cotrim 46\%, Amoxicillin and clavulanic acid $0 \%$, Cefixime $36 \%$, Cefuroxime 19\%, Ceftriaxone 22\%, Azithromycin 25\%, Nitrofurantoin $66 \%$, Ceftazidime 19\%, Ciprofloxacin 47\%, Nalidixic acid 36\%, Levofloxacin $71 \%$, Colistin 79\%, Gentamycin 80\%, Netilmycin $80 \%$, Amikacin $80 \%$ and Meropenam $40 \%$. On the other hand, resistance was Cephradine 100\%, Cefotaxim 100\%, Imepenam 0\%, Cotrim $54 \%$, Amoxicillin and clavulanic acid $100 \%$, Cefixime $64 \%$, Cefuroxime $81 \%$, Ceftriaxone $78 \%$, Azithromycin $75 \%$, Nitrofurantoin 34\%, Ceftazidime $81 \%$, Ciprofloxacin 53\%, Nalidixic acid 64\%, Levofloxacin 29\%, Colistin 21\%, Gentamycin 20\%, Netilmycin 20\%, Amikacin 20\% and Meropenam $60 \%$. So, the most sensitive drug was Imepenam $100 \%$ and the most resistant drug were Cephradine and Cefotaxim $100 \%$ resistance against urinary pathogens. Association between antibiotic taken without prescription and antibiotic taken with prescription was highly significant.

Table 1. Socio- demography of the patients. $(n=519)$.

\begin{tabular}{lll}
\hline Age (years) & $\mathbf{n}$ & $\mathbf{\%}$ \\
\hline$<1$ & 27 & 5.2 \\
$1-2$ & 52 & 10 \\
$2-3$ & 71 & 13.6 \\
$3-4$ & 79 & 15.2 \\
$4-5$ & 87 & 16 \\
$5-6$ & 105 & 20 \\
$6-7$ & 29 & 5.5 \\
\hline
\end{tabular}

\begin{tabular}{lll}
\hline Age (years) & n & \% \\
\hline $7-8$ & 17 & 3.2 \\
$8-9$ & 17 & 3.2 \\
$9-10$ & 09 & 1.7 \\
$10-11$ & 126 & 24.2 \\
Male & 167 & 32 \\
Female & 352 & 68 \\
Pre-school going & 229 & 44 \\
School going & 290 & 56 \\
\hline
\end{tabular}

Table 2. Monthly income of the parents of the participants. $(n=519)$.

\begin{tabular}{lll}
\hline Father's income (monthly) & $\mathbf{n}$ & $\mathbf{n} \%$ \\
\hline$<5000$ & 25 & 4.8 \\
$5000-10000$ & 77 & 14.8 \\
$10000-15000$ & 142 & 27.3 \\
$15000-20000$ & 158 & 30.4 \\
$20000-25000$ & 53 & 10.2 \\
$25000-30000$ & 45 & 8.6 \\
$>30000$ & 19 & 3.6 \\
\hline
\end{tabular}

Table 3. The patients presented complaints for abdominal pain. $(n=519)$.

\begin{tabular}{ll}
\hline Variable & $\mathbf{n \%}$ \\
\hline Fever & $219(42)$ \\
Constipation & $311(59)$ \\
Increased frequency of micturition & $175(34)$ \\
Taking antibiotics without prescription & $416(80)$ \\
Anatomical abnormity dribling & $40(8)$ \\
difficulty in micturition & $80(15)$ \\
Street food taking & $319(61)$ \\
\hline
\end{tabular}

Table 4. Urine culture result of the study participants. $(n=519)$.

\begin{tabular}{lll}
\hline Total Patient With abdominal pain & N (519) & N\% (100) \\
\hline Taken antibiotics without prescription & 416 & 80.15 \\
Culture positive (+) & 205 & 49.27 \\
Culture positive (-) & 211 & 50.73 \\
Taken antibiotics with prescription & 103 & 19.15 \\
Culture positive (+) & 13 & 12.62 \\
Culture positive (-) & 90 & 87.38 \\
\hline
\end{tabular}

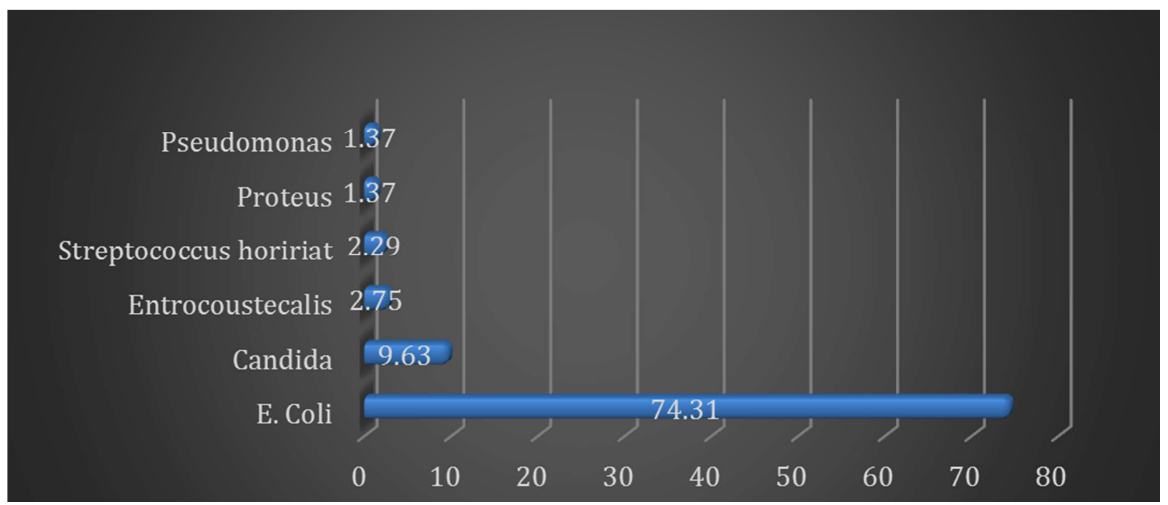

Figure 1. Distribution of bacterial organisms of the participants. $(n=519)$.

Table 5. Antimicrobial Resistance (\%) of Isolated Uropathogenic Bacteria $(n=519)$.

\begin{tabular}{lllll}
\hline Name of drugs & No of culture per pt & Sensitive & \% of Sensitive & Resistant \\
\hline Cephradine & 17 & 0 & 0 & 17 \\
Cefotaxim & 19 & 0 & 0 & 19 \\
Imepenam & 19 & 19 & 100 & 0 \\
Cotrim & 114 & 54 & 46 & 0 \\
\hline
\end{tabular}




\begin{tabular}{|c|c|c|c|c|c|}
\hline Name of drugs & No of culture per pt & Sensitive & $\%$ of Sensitive & Resistant & $\%$ of resistant \\
\hline Amoxicillin and clavulanic acid & 17 & 0 & 0 & 17 & 100 \\
\hline Cefixime & 193 & 69 & 36 & 123 & 64 \\
\hline Cefuroxime & 184 & 34 & 19 & 150 & 81 \\
\hline Ceftriaxone & 195 & 43 & 22 & 152 & 78 \\
\hline Azithromycin & 175 & 44 & 25 & 131 & 75 \\
\hline Nitrofurantoin & 193 & 127 & 66 & 65 & 34 \\
\hline Ceftazidime & 192 & 36 & 19 & 156 & 81 \\
\hline Nalidixic acid & 193 & 69 & 36 & 124 & 64 \\
\hline Levofloxacin & 193 & 87 & 71 & 36 & 29 \\
\hline Colistin & 123 & 86 & 79 & 36 & 30 \\
\hline Gentamycin & 87 & 71 & 80 & 16 & 20 \\
\hline Netilmycin & 87 & 70 & 80 & 17 & 20 \\
\hline Amikacin & 87 & 70 & 80 & 17 & 20 \\
\hline Meropenam & 87 & 35 & 40 & 52 & 60 \\
\hline
\end{tabular}

Table 6. Association between antibiotic taken without prescription and antibiotic taken with prescription. $(n=519)$.

\begin{tabular}{lll}
\hline & Taken antibiotics without prescription & Taken antibiotics with prescription \\
\hline Culture positive (+) & 205 & 13 \\
Culture positive (-) & 211 & 90 \\
\hline
\end{tabular}

$\mathrm{SN}=$ Significant.

\section{Discussion}

Uropathogens are gaining resistance at an increased rate to commonly used antimicrobial agents. The sensitivity pattern is changing day by day and it varies from hospital to hospital. Constant survey of antimicrobial resistance is very important for empirical treatment of UTI. [13-14]This study showed drug resistant UTI presented as recurrent abdominal pain in younger children is highly associated with frequently use of antibiotics without prescription through a survey with a number of 519 pre-school and school going children. The study was carried on at in-out patients department of Kurmitola General Hospital: A Tertiary Care Hospital in Dhaka, Bangladesh during the period from January 2018 to December 2018. All the children were the patients of UTI recurrent abdominal pain. Among them $68 \%$ were female and $32 \%$ were male. Pre-school going children were 229 (44\%) and school going were 290 (56\%). Again the children were divided into two groups on the basis of taking antibiotics with prescription and without prescription. The number of children took antibiotics without prescription was $416(80 \%)$ [31] and the number of students never took antibiotics without prescription was $103(19.2 \%)$. Then the urine of the children who took antibiotics without prescription was investigated [22-24]. The R/E was below 5 $(62.6 \%)$ of the children and $(37.4 \%)$ was above 5 . Then the culture was also investigated of 416 children. Among them positive culture was 205 (49.2) and negative culture was 211 (50.8\%). The most common pathogens was found E Coli $74.31 \%$ which was mainly responsible for UTI infections in the present study. The same result was found in the study of Francesco MA and Ravizzola et al and Mendo A and Antunes J et al and Costa M, Pereira PM et al. [19-21]. Then a few number of drugs' (antibiotics) sensitivity and resistance were evaluated on the no of culture of per patient, culture positive (+) $13(12.6 \%)$ and culture negative (-) 90 (87.4).
Only two drugs were identified as $100 \%$ resistant and they were Cephradine, Amoxicillin and clavulanic acid and Cefotaxim. However, in the previous studies coli and Klebsiella spp. have also been isolated as the most common pathogens responsible for UTI among children. Anyway, E coli was the most frequent organism isolated in this study. This is similar to results of investigations in other countries. [15-16]. In this study, higher resistance rates to all antibiotics tested with the exception of amikacin, colistin, imepenum and Meropenum may be explained by high and uncontrolled usage of these antimicrobial agents, especially thirdgeneration cephalosporins during the past few years in our country and these antibiotics were widely prescribed not only for UTI but also for other infections. E coil is steel the most common $(70 \%)$ cause of UTI and the klebsiella being the second (13.6\%). In a study conducted in India in 2007 has shown the distribution of urinary pathogen as follows. E, colli 63\%, Klebsiella-spp $15.9 \%$ and Pseudomonas aeruginosa $5.30 \%$. In the present study result of antibiotic susceptibility test reveal that the urinary isolates were $100 \%$ resistance three drugs and they were Cephradine, Cefotaxim and Amoxicillin and clavulanic acid. Previous study showed that the susceptibility of E-coli to impenum ranged from 98$100 \% .17-18$. In the present study, most of the isolates were found Cephradine (100\%) followed by Cefotaxim (100\%), Imepenam (0\%), Cotrim (54\%), Amoxicillin and clavulanic acid (100\%), Cefixime (64\%), Cefuroxime (81\%), Ceftriaxone (78\%), Azithromycin (75\%), Nitrofurantoin (34\%), Ceftazidime (81\%), Ciprofloxacin (53\%), Nalidixicacid (64\%), Levofloxacin (29\%), Colistin (30\%), Gentamycin (20\%), Netilmycin (20\%), Amikacin (20\%) and Meropenam (60\%). All the isolates showed strong resistance to Cephradine, Cefotaxim and Amoxicillin and clavulanic acid. Therefore, it was successfully revealed to the researcher that the drug resistant UTI presented as recurrent abdominal pain in Bangladeshi Children is highly associated with 
frequently use of antibiotics without prescription.

Limitation of This Study

This study was done only in Dhaka city with limited sample size and also short period of time. So, the study result may not reflect the scenarios of the whole country.

\section{Conclusion}

This study provides valuable information regarding current distribution of urinary pathogens and their antimicrobial resistance pattern and successfully showed drug resistant UTI presented as recurrent abdominal pain in Bangladeshi Children is highly associated with frequently use of antibiotics without prescription. So, we suggest that empirical antibiotic selection should be based on knowledge of the local prevalence of bacterial organism and antibiotic resistance and none should have antibiotics without prescription.

\section{Conflict of Interest}

None Declared.

\section{Funding}

Self.

\section{Approval}

From respective department.

\section{Acknowledgements}

The authors wish to thank the microbiology laboratory doctors \& staff, as well as the junior doctors for their kind support to collect data during this study.

\section{References}

[1] Platt, R, Polk, BF, Murdock, B et al, Mortality associated with nosocomial urinary-tract infection. $N$ Engl J Med. 1982; 307: 637-642.

[2] Adjei and Copoku, "Urinary tract infections in African infants," International Journal of Antimicrobial Agents, 2004; 24 (1): S32-S34.

[3] F Mortazavi and NShahin, "Changing patterns in sensitivity of bacterial uropathogens to antibiotics in children," Pakistan Journal of Medical Sciences, 2009; 25 (5): 801-805.

[4] Dulczak S, Kirk J Overview of the evaluation, diagnosis and management of urinary tract infections in infants and children. UrolNurs 2005; 25: 185-191.

[5] Winberg, J, Andersen, JH, Bergstrom, T et al, Epidemiology of symptomatic urinary tract infection in childhood. ActaPathol Scand. 1974; 252: 1-20.

[6] AlperAsscher, AW. Urinary tract infection in childhood J R Coll Physicians Lond. 1981; 15: 232-238.
[7] F. E. Abdullah, AA, Memon, MY, Bandukda, and M Jamil, "Increasing ciprofloxacin resistance of isolates from infected urines of a cross-section of patients in Karachi," BMC Research Notes, 2012; 5 (1): 696-701.

[8] Alemu, F Moges, Y Shiferaw, K Tafess, AKassu, B. Anagaw, et al., "Bacterial profile and drug susceptibility pattern of urinary tract infection in pregnant women at University of Gondar Teaching Hospital, Northwest Ethiopia," BMC Research Notes, 2012; 5 (1): 197-204.

[9] G. Schmiemann, I Gagyor, E Hummers-Pradier, and J. Bleidorn, "Resistance profiles of urinary tract infections in general practice-an observational study," BMC Urology, 2012; 12 (1): 33-38.

[10] S. Farajnia, MY Alikhani, R Ghotaslou, B Naghili, and ANakhlband, "Causative agents and antimicrobial susceptibilities of urinary tract infections in the northwest of Iran," International Journal of Infectious Diseases,, 2009; 13 (2): $140-144$.

[11] N. Kashef, GE Djavid, and SShahbazi, "Antimicrobial susceptibility patterns of community-acquired uropathogens in Tehran, Iran," Journal of Infection in Developing Countries, 2010; 4 (4): 202-206.

[12] Pieore RK, Patrice M. Lazre K. Antibiotic resistance in E. coli isolated from women genitila and tend of minimal inhibiting concentration in a semi-urban population. Current research journal biological science 2012: 4 (16). 696-701.

[13] Hryniewicz K, Szczypa K, SulikowskaA et al. Antibiotic Susceptibility of bacterial stains isolated from urinary tract infection in Polland. J. Antimicrobchemother 2001; 47 (6): 773-80.

[14] Farjana R, Sadia C, Mojibur R, Ahmed D, Anwar H. Antimicrobial resistance pattern of gram negative bacteria causing urinary tract infection, Stamford journal of Pharmaceuticals sci 2009; 2 (1): 44-50.

[15] Lizama CM, Luco IM, Reichhard TC, et al. Urinary tract infection in a pediatrics emergency department: frequency and clinical parameters. Rev ChilenaInfectol 2005; 22: 235241 .

[16] Lutter SA, Currie ML, Mitz LB, et al. Antibiotic resistance patterns in children hospitalized for urinary tract infections. Arch PediatrAdolesc Med 2005; 159: 924-928.

[17] Salah AA, Ahmed SS, Ahmed M, Naser A, Ruhul A M. Changing Trends in Uropathogens and their antimicrobial sensitivity pattern. Bangladesh J Med Microbial 2009; 03 (01); 9-12.

[18] Tantry BA, Rahiman S. Antibacterial resistance and trend of urinary tract pathogens in commonly used antibiotics in khasmir Valley; West Indian med J 2012; 61 (7): 43-44.

[19] Francesco MA, Ravizzola G, Peroni L, Negrini R, Manca N: Urinary tract infections in Brescia, Italy: Etiology of $n$ uropathogens and antimicrobial resitance of common uropathogens. Med Sci Monit 2007, 6: 136-144.

[20] Mendo A, Antunes J, Costa M, Pereira PM, Monteiro C, Gomes CF, Gomes JF: Frequência de Infecções urinárias em Ambulatório - dados de um laboratório de Lisboa. Parte I. Revista Lusófona de Ciências e Tecnologia da Saúde 2008, 5: 216-223. 
[21] Costa M, Pereira PM, Bolotinha C, Ferreira A, Cardoso R, Monteiro C, Gomes CF, Gomes JF: Frequência e Susceptibilidade Bacteriana em Infecções Urinárias -dados de um laboratório de Lisboa. Parte II. Rev Lusófona de Ciências e Tecnologias da Saúde 2009, 6: 87-103.

[22] Stephens GM, Akers S, Nguyen H, Woxland H. Evaluation and management of urinary tract infections in the school-aged child. Prim Care 2015; 42 (1): 33-41.

[23] Bonny AE, Brouhard BH. Urinary tract infections among adoles- cents. Adolesc Med 2005; 16 (1): 149-61.

[24] Williams GJ, Macaskill P, Chan SF, Turner RM, Hodson E, Craig JC. Absolute and relative accuracy of rapid urine tests for urinary tract infection in children: A meta-analysis. Lancet Infect Dis 2010; 10 (4): 240-50.

[25] Chang SL, Shortliffe LD. Pediatric urinary tract infections. Pediatr Clin North Am 2006; 53 (3): 379-400.
[26] Simões e Silva AC, Oliveira EA. Update on the approach of uri- nary tract infection in childhood. J Pediatr (Rio J) 2015; 91 (6 Suppl 1): S2-S10.

[27] Korbel L, Howell M, Spencer JD. The clinical diagnosis and man- agement of urinary tract infections in children and adolescents. Paediatr Int Child Health 2017; 37 (4): 273-9.

[28] Schlager TA. Urinary tract infections in infants and children. Mi- crobiol Spectr 2016; 4 (5). doi: 10.1128/microbiolspec. UTI-0022- 2016.

[29] Shaikh N, Hoberman A. Urinary tract infections in children: Epi- demiology and risk factors. In: Post TW, Ed. UpToDate. Waltham, MA. (Accessed on August 10, 2018).

[30] CLSI Clinical and Laboratory Standard Institute (CLSI), Performance standards for antimicrobial susceptibility testing, Wayne, A, USA. 2010.

[31] Nelson, Edition-21, chapter-553, page-2789. 